Virginia Commonwealth University vCU Scholars Compass

2011

\title{
Challenges and Benefits of Using a Virtual Community to Explore Nursing Concepts Among Baccalaureate Nursing Students
}

Linnea L. Carlson-Sabelli

Rush University

Jean F. Giddens

Virginia Commonwealth University, jgiddens@vcu.edu

Louis Fogg

Rush University

Ruth A. Fiedler

Rush University

Follow this and additional works at: http://scholarscompass.vcu.edu/nursing_pubs

Part of the Nursing Commons

Copyright (C) De Gruyter

Downloaded from

http://scholarscompass.vcu.edu/nursing_pubs/1

This Article is brought to you for free and open access by the School of Nursing at VCU Scholars Compass. It has been accepted for inclusion in School of Nursing Publications by an authorized administrator of VCU Scholars Compass. For more information, please contact libcompass@vcu.edu. 


\title{
International Journal of Nursing Education Scholarship
}

\section{Challenges and Benefits of Using a Virtual Community to Explore Nursing Concepts Among Baccalaureate Nursing Students}

\author{
Linnea L. Carlson-Sabelli* Jean Foret Giddens ${ }^{\dagger}$ \\ Louis Fogg ${ }^{\ddagger} \quad$ Ruth A. Fiedler**
}

*Rush University College of Nursing, linnea_carlson-sabelli@ rush.edu

†Univeristy of New Mexico College of Nursing, jgiddens@salud.unm.edu

${ }^{\ddagger}$ Rush University College of Nursing, louis_fogg@ @ush.edu

**Rush University, ruth_fiedler@ rush.edu 


\title{
Challenges and Benefits of Using a Virtual Community to Explore Nursing Concepts Among Baccalaureate Nursing Students*
}

\author{
Linnea L. Carlson-Sabelli, Jean Foret Giddens, Louis Fogg, and Ruth A. Fiedler
}

\begin{abstract}
This research study examines learner perceptions of benefits and challenges associated with the Neighborhood (NBH), an innovative pedagogy that fosters learner engagement and integration of nursing concepts using a "virtual community" as an alternative to lecture. First-semester students from five baccalaureate nursing programs that used the NBH intervention were divided into high $(\mathrm{N}=78)$ and low faculty use $(\mathrm{N}=203)$ groups. Qualitative analysis revealed that the NBH intervention promoted application of concepts to real life situation was engaging and "eyeopening," allowing students to understand health care issues from a variety of perspectives. A major challenge was busy work generated by faculty assignments unrelated to enhancing conceptual clarity. Statistical analyses indicate that benefits and challenges grow together; benefits outweigh challenges and net benefit increases with increased faculty use. This study highlights the need to provide initial and ongoing training and support to faculty at schools who adopt this intervention.
\end{abstract}

KEYWORDS: neighborhood, simulation, engagement, conceptual learning

\footnotetext{
*This study was partially funded by an intramural research grant from the University of New Mexico College of Nursing. This study involves the evaluation of a commercial product. The manufacturer did not provide financial support for this study. The lead author does not have a financial or proprietary interest in the materials presented herein. A co-author, Dr. Giddens, has a financial interest in the product in the form of royalties.
} 
There has been a clear and consistent message within the nursing education literature regarding the need to shift from predominantly instructorcentered, learner-passive teaching strategies to student-centered, integrative learning activities. During the past decade, one of the most visible and successful integrative student-centered approaches has been simulation. Although simulation was almost immediately valued by faculty and students, challenges existed in successful implementation, such as cost, infrastructure, and expertise. And although simulation has bolstered clinical and laboratory learning, lecture continues to be the predominant teaching approach in classroom settings (National League for Nursing, 2005; Young \& Diekelmann, 2002). For this reason, there is a continued need to develop and test new applications for didactic and online settings.

The "virtual community" is an emerging pedagogical application that has shown promise in fostering learner engagement and integrative applications in all learning environments (didactic, online, and clinical). Faculty and students can be expected to initially find benefits and challenges associated with its use. The purpose of this article is to present the findings of a study on the learner benefits and challenges associated with the use of a virtual community, incorporating both statistical and qualitative methods as a basis for analysis.

\section{REVIEW OF LITERATURE}

In the context of pedagogical applications in nursing, the term virtual community refers to a fictional web-based community featuring character stories that focus on health care issues. Three different virtual communities developed for nursing education (Mirror Lake, The Neighborhood, and Stillwell) have been previously discussed in the literature (Curren, Elfrink, \& Mays, 2009; Giddens, 2007; Walsh, 2010). This study involved the use of The Neighborhood virtual community. The Neighborhood consists of an online community of families struggling with health-related issues. It features the stories of 40 characters (34 household characters and 6 nurse characters) that are updated each week over three academic semesters. Video clips, medical records, and breaking news are incorporated into The Neighborhood experience. Nursing students are encouraged to visit the online material frequently to keep abreast of current events that impact the health of its members. Students get to know the families and their health dilemmas in the context of community life, while faculty create interactive learning classroom, homework, and evaluative activities based on the longitudinal case material to illustrate a variety of interrelated nursing concepts. The stories are based on the demographic incidence and prevalence of illness in the USA, 
providing a platform to explore concepts related to a representative spectrum of illnesses a nurse might be expected to encounter in everyday practice.

\section{Theoretical Underpinnings}

The philosophical and theoretical underpinnings of The Neighborhood intervention have been well delineated in the literature. The Neighborhood is an exemplar of multicontextual learning (Hall, 1984, Ibarra, 2001) using a conceptbased learning methodology (Giddens, 2008). Concept-based multicontextual learning differs dramatically from content-based, low-context learning methodologies prevalent in nursing education today (Giddens \& Brady, 2007). In a content-based, low-context learning environment, faculty might assign readings and lecture about a specific illness, for example, diabetes. Using a PowerPoint presentation, the lecturer provides an overview of the illness and lists of symptoms, complications, treatment strategies, and issues faced by a person with the illness. A case example is presented to highlight important facts. In contrast, teachers in concept-based, high-context learning environments expect students to grapple with concepts rather than memorize facts about illness and treatment. Stories from the virtual community serve as the case material for exploring such concepts as symptom emergence, treatment compliance, prevention, nutrition, skin care, acidosis, ketosis, metabolic pathways, medication interactions, amputation, rehabilitation, symptom management, health promotion, and so forth. Concepts learned through the story of characters' illness experiences are also generalized to apply to other situations.

Multicontextual learning brings multiple modes of communication to the learning environment beyond merely words. Instead of presenting content mainly as lecture, faculty engage students in constructing a care plan, gathering material to be used in a patient teaching-learning situation, role playing alternative scenarios, engaging in debate, and so forth. Context diversity is achieved by assuring that a variety of communication modes are used in the learning environment. Activity becomes as predominant as reading and writing as method of instruction and formative and summative evaluation. Interactive learning methods cater to the strengths of high-context learners, whereas the learning preferences of low-context learners are still fulfilled through course texts and written assignments. Merging conceptual and multicontextual learning strategies provides students with a lived experience not achievable through simply hearing or reading an isolated case study. Students form bonds with the characters, and the emotional engagement is expected to heighten the memory of the learned material (Zull, 2004). Deep learning of generalizable concepts is promoted. 
Because the virtual community is an emerging pedagogy, research related to its use in nursing education is currently limited to three published articles. One study involved a sample of undergraduate baccalaureate nursing students $(N=$ 248) who used The Neighborhood in one nursing program. Researchers reported that older students (aged 24 years and older) had a greater preference for the application compared with younger students and that student-perceived benefits increased over time. In addition, minority students reported greater perceived benefits compared with White students, and students who expected to earn a course grade below an A perceived greater benefits and a greater perception that the intervention helped them to connect character problems to course concepts compared with students expecting to earn an A in the course (Giddens, Shuster, \& Roehrig, 2010).

In a secondary analysis focusing on qualitative data, the same research team followed a cohort of 40 undergraduates using The Neighborhood over three successive semesters. A content analysis of participant responses generated by open-ended survey questions revealed two primary themes: an emotional connection to specific characters or families and integration of characters and events into learning activities. A third thematic category, concerns, revealed that students were challenged by the large number of characters to keep track of and the amount of time needed to read story updates each week. The researchers concluded that virtual communities may provide a viable strategy for teaching nursing concepts and their application but recognized the need for further research, including the use of student samples from other schools (Shuster, Giddens \& Roehrig, 2011).

A third study involved 350 nursing students who used The Neighborhood intervention for one academic semester. The researchers found a positive relationship between faculty use and perceived benefits reported by students. Additionally, underrepresented minority students reported greater engagement compared with White/Asian students in the sample (Giddens, Fogg, \& CarlsonSabelli, 2010). The current study compares and contrasts student perceptions of the benefits and challenges of using The Neighborhood intervention in 5 baccalaureate nursing programs.

\section{RESEARCH QUESTIONS}

The introduction of new teaching and learning strategies requires an investigation of the application as it relates to instructors and learners. The specific research questions for this study were: 
International Journal of Nursing Education Scholarship, Vol. 8 [2011], Iss. 1, Art. 10

1. What are the primary benefits and challenges reported by learners using a virtual community?

2. What is the relationship between perceived learner benefits and challenges?

\section{RESEARCH METHODS}

\section{Research Design and Sample}

This study employed a mixed-method design that included an analysis of qualitative themes within the context of quantitative measures using a statistical and "diamond of opposites" approach. All first-semester students from five participating baccalaureate nursing programs using The Neighborhood virtual community $(N=350)$ were invited to participate in the study. The final study sample was narrowed to 281 students who actually reported using The Neighborhood intervention and completed all surveys. The study had institutional review board approval from all five sites. The researchers did not have an affiliation with any of the nursing schools participating in this study.

\section{Intervention and Data Collection Procedure}

Faculty teaching the first-level courses agreed to use The Neighborhood as a teaching application within their courses all semester. Although there was no specific mechanism in place to control the frequency or quality of use of learning activities, an external faculty consultant and the investigator at each site provided ongoing encouragement for use. Students were informed that their nursing school was involved in a multisite pilot evaluation of The Neighborhood and that it would be used in their first-level courses. All students who agreed to participate completed a demographic survey at the beginning of the semester and an exit survey at the end of the semester. Participation was voluntary and anonymous and did not impact the course grade. Due to a known conflict of interest, the primary investigator of this study did not directly collect or analyze data. Surveys were collected by an onsite investigator at each participating nursing program and sent to an external research team for analysis.

\section{Instrument}

The 19-item exit survey represented four constructs: perceived learning utility, perceived benefits and challenges, learner engagement, and cultural 
awareness. Six items were specifically used to answer the research questions posed in this article. Two items asked students to rate the strength of their personal benefits and the strength of the personal challenges encountered in using the virtual community as a learning tool. Each of these items was rated on a 10point scale $(0=$ no benefit $/$ no challenges, $10=$ highly beneficial/highly challenging) and was followed by an open-ended question requesting participants to describe the most beneficial and most challenging aspect of The Neighborhood. An additional open-ended question asked: "What else would you like us to know about your learning experiences with The Neighborhood?"

One survey item was used to determine study inclusion and as a grouping variable. Specifically, participants rated the frequency of faculty use (attending a class in an average week where the instructor provided an activity or assignment based on The Neighborhood $)$ on a 5 -point Likert scale $(1=$ never, $2=$ rarely, $3=$ sometimes, $4=$ often, $5=$ very often). Participants who rated the frequency of faculty use as "never" were excluded from further analysis. Participants who actually used the intervention were grouped into one of two groups: low users (faculty use $=$ rarely or sometimes) and high users (faculty use $=$ often or very often). Mean faculty use scores for each school were calculated to distinguish and compare the school with highest and lowest faculty use.

\section{Analysis Procedures}

A quantitative, qualitative, and diamond of opposites approach was used for analysis. Quantitative analysis was used to compare the mean benefits and challenges scores between low-use and high-use groups and between low-use and high-use schools. A qualitative analysis was done using a content analysis process (Stemler, 2001) to identify themes from the open-ended questions about benefits and challenges. An emergent coding method was used to group the benefits and challenges comments into themes. Initial analysis involved the identification of exhaustive thematic categories by two researchers independently. The categories were merged into eight benefits categories and eight challenges categories. Each comment was reviewed again and re-coded according to the new categories by the researchers independently and then together to reconcile differences. The themes were examined for overlap and exclusivity and were collapsed into three benefits themes and three challenges themes.

A diamond of opposites analysis was used to clarify the meaning of the benefits and challenges ratings. This method of analysis was originally developed for use in sociometry (Carlson-Sabelli, Sabellli, \& Hale, 1994; Carlson-Sabelli, Sabelli, Patel, \& Holm, 1992) and is based on a process theory view (Sabelli, 
1989, 2005). Process theory suggests that opposites coexist and can grow together, and if this is true, then one must measure both to get a realistic view of a process. Analysis first requires researchers to identify and measure coexisting complementary opposites in a process and analyze them together. It then requires the calculation of two new variables representing energy and direction implied by the opposite ratings. In this study, the energy variable was calculated by adding the benefits rating to the challenges rating; this represented the combined strength of the preferences toward using and toward rejecting the intervention. The direction variable was calculated by subtracting the challenges rating from the benefits rating. A positive score indicated net benefits, and a negative score indicated that the challenges were greater than the benefits.

\section{FINDINGS}

\section{Demographics}

There were 281 participants from five nursing programs included in the final study sample. The age $(M=24$ years, $S D=6.53$, range $=19-56)$ and gender ( $87.5 \%$ female, $12.5 \%$ male) representation of the sample was typical of students enrolled in undergraduate nursing programs. The racial/ethnic distribution of the sample was $52 \%$ White $(n=146) ; 19.2 \%$ African American $(n=54) ; 13.5 \%$ Asian $(n=38), 8.2 \%$ Hispanic $(n=23)$, and 7\% Pacific Islander, Native American, mixed race, or other $(n=20)$. Slightly more than one third of the sample $(38.8 \%, n=109)$ reported having prior health care experience.

\section{Differences in Benefits and Challenges Among High-Use and Low-Use Groups}

Of the 281 participants, $203(72 \%)$ reported that in a typical week, the faculty used The Neighborhood rarely or sometimes and were assigned to the lowuse group. The other $78(28 \%)$ participants reported using the intervention often or very often and were assigned to the high-use group. A $t$ test was applied to compare the mean benefits and challenges scores between the two groups. The high-use group had higher mean benefits scores $(M=4.57, S D=2.45)$ compared with the low-use group $(M=2.88, S D=2.27)$; this difference was statistically significant $t(276)=-5.4, p=0.00$. Challenges scores were also significantly higher in the high-use group than the low-use group $t(271)=-3.6, p=0.00$. 


\section{Differences in Benefits and Challenges Among High-Use and Low-Use Schools}

In a secondary analysis of data, we compared the mean benefits and challenges scores among participants at the school with the highest mean faculty use $(M=3.85, S D=0.88)$ and the school with the lowest mean faculty use $(M=$ $1.95, S D=1.45$ ). The results (shown in Table 1) highlight the relationships between mean faculty use and student use (among students reporting use). Significant differences among users were noted between the two schools for benefits, $t(94)=-2.14, p=0.035$, but not for challenges, $t(92)=0.67, p=0.5$. Students at both the lowest use and highest use schools reported that the intervention was more beneficial than challenging. The net benefits (difference between benefits and challenges means) at the highest use school (1.57) were greater than the net benefits at the lowest use school (0.14).

Table 1

Mean Benefits Scores and Challenges Scores Among Users

\begin{tabular}{|c|c|c|c|c|}
\hline $\begin{array}{c}\text { Number of } \\
\text { Participants by } \\
\text { School }\end{array}$ & $\begin{array}{c}\text { Mean Benefits } \\
\text { Score Among } \\
\text { Users }\end{array}$ & $t$ test & $\begin{array}{c}\text { Mean Challenges } \\
\text { Score Among } \\
\text { Users }\end{array}$ & $t$ test \\
\hline $\begin{array}{l}\text { Lowest Use } \\
\text { School }(n=62)\end{array}$ & & \multirow{4}{*}{$\begin{array}{l}t(94)= \\
-2.14, \\
p=0.035\end{array}$} & & \multirow{4}{*}{$\begin{array}{l}t(92)=0.67, \\
p=0.5\end{array}$} \\
\hline $\begin{array}{l}\text { No use }=31 \\
\text { Low use }=23\end{array}$ & $\begin{array}{l}M=3.17, S D=2.37 \\
(n=32)\end{array}$ & & $\begin{array}{l}M=3.03, S D=2.36 \\
(n=30)\end{array}$ & \\
\hline High use $=8$ & & & & \\
\hline $\begin{array}{l}\text { Highest Use } \\
\text { School }(\boldsymbol{n}=\mathbf{6 6}) \\
\text { No use }=0 \\
\text { Low use }=25 \\
\text { High use }=41\end{array}$ & $\begin{array}{l}M=4.29, S D=2.38 \\
(n=66)\end{array}$ & & $\begin{array}{l}M=2.72, S D=2.0 \\
(n=64)\end{array}$ & \\
\hline
\end{tabular}

Note. Although both lowest and highest use schools had a similar number of participants, almost $50 \%$ of the students at the lowest use school reported not using the intervention at all. Also, some of the participants at both sites did not provide scores for both benefit and challenge items.

\section{Qualitative Themes Associated With Benefits and Challenges}

Our content analysis of qualitative themes revealed three benefits themes: (1) an Enlarged View of factors that impact health care, (2) Clarity of Concept Application to real-life situations, and (3) Engagement in which characters and their situations become alive through ongoing stories. 
Enlarged View. Among those who provided comments related to benefits, $42 \%$ indicated that the intervention enlarged their view of factors that impact the health of individuals and families across cultures and time and of how disease processes develop. They also reported an expanded view of community resources. The intervention was described as "eye-opening," allowing them to see and understand health care issues from a variety of perspectives (the patient, family members, and nurse). Select comments, such as "Identifying people, disease characteristics and how they impact their lives outside the hospital setting" and "Being given a situation and being able to look at every aspect of that person's life to get a good picture of what was going on with them mentally to physically," are supporting examples of this theme.

Clarity of Concept Application. The second benefits theme, Clarity of Concept Application, was reflected in $23 \%$ of commenting participants. They indicated that the intervention enhanced clarity of the material and helped them to understand the concepts more deeply. Specific comments included: "Having cases was helpful in forming concepts during class and applying them to real life situations," "Following families with different issues helps with some of the concepts \& skills learned in class," "Various detailed situations and how several could relate to one concept," and "Helpful in understanding how to formulate nursing diagnosis."

Engagement. Engagement is the third benefits theme, cited by $20 \%$ of participants providing comments. The Neighborhood created an enjoyable learning experience that participants found interesting and entertaining because the circumstances of the various patients were brought to life. Supporting comments included: "Makes learning about different disorders become alive and interesting through stories," "Seeing the patient's [video] helps me identify with them and not see them as just a 'case' on paper," "My interest grew after learning about the conditions the patients had."

Four challenges themes were revealed through analysis and included: (1) Keeping Up with so much information, (2) Inefficient Use of Time and busy work, (3) Boring and lack of a mechanism to attain additional information when curious, and (4) Positive Challenges.

Keeping Up. The first challenges theme, Keeping Up, was reported by $33 \%$ of the participants providing comments related to challenges. Participants stated that it was challenging to keep up with all the information within the stories 
or "to glean the whole picture of the patient's condition." Additional comments included "Putting it together" and "Keeping up with all the characters."

Inefficient Use of Time. The second challenges theme, Inefficient Use of Time, was reflected in $32 \%$ of the comments. The participants conveyed that the intervention took too much time, was an inefficient use of time, or was associated with too much busy work. Many comments suggested that the underlying issue was not the virtual community itself but rather that it was perceived that faculty did not value or incorporate it well. Specific comments supporting this theme included: "If incorporated into course work it could be very beneficial," "Instructors did not really utilize it to teach so it felt like just busy work," and "With current course structure The Neighborhood is just extra work. If incorporated into course work it could be very useful."

Boring. The third challenges theme, Boring, was cited by $28 \%$ of respondents. Comments in the category included "Not challenging," "Wanted to get more information through interaction with characters," and "The stories needed to be more detailed and quicker paced." Many participants implied that they felt frustrated because they were unable to interact with the "patients" to get more information.

Positive Challenges. Students reported: "I think any challenges I faced had to do with encountering new information as a nursing student," "I found conceptual thinking to be challenging, but important," or I was "challenged by all the new information, by having to apply and understand new information." Positive challenges were reported only by students at the school with the highest faculty use.

Both similarities and differences existed for the benefits and challenges themes among participants at the low-use and high-use schools. Enlarged View was the highest reported benefits theme at both schools. However, the students at the highest use school reported four times as much benefit in the area of Clarity of Concept Application, and participants at the lowest use school had twice the number of comments linking to Engagement. Challenges themes were virtually identical between the lowest use and highest use schools, with the exception that students at the highest use school also described many positive challenges.

\section{Diamond of Opposites Results}

Data analysis using the diamond of opposites approach is presented in Figure 1. The diamond plot provides information about individual student 
responses not captured in averages. The plots of the direction variable (x-axis) and the energy variable (y-axis) are constructed to show the distribution of individual responses on a phase plane. The coordinate plot depicts the sum and difference of opposites (not the opposite values themselves). The data points are contained within a diamond shape on the coordinate plane and can be roughly divided into four quadrants. Data points in the bottom quadrant indicate students who rated The Neighborhood low in both benefits and challenges. The left quadrant represents students who rated challenges greater than benefits, whereas the right quadrant represents students who rated benefits higher than challenges. The top quadrant contains the data points of students who rated both benefits and challenges high.
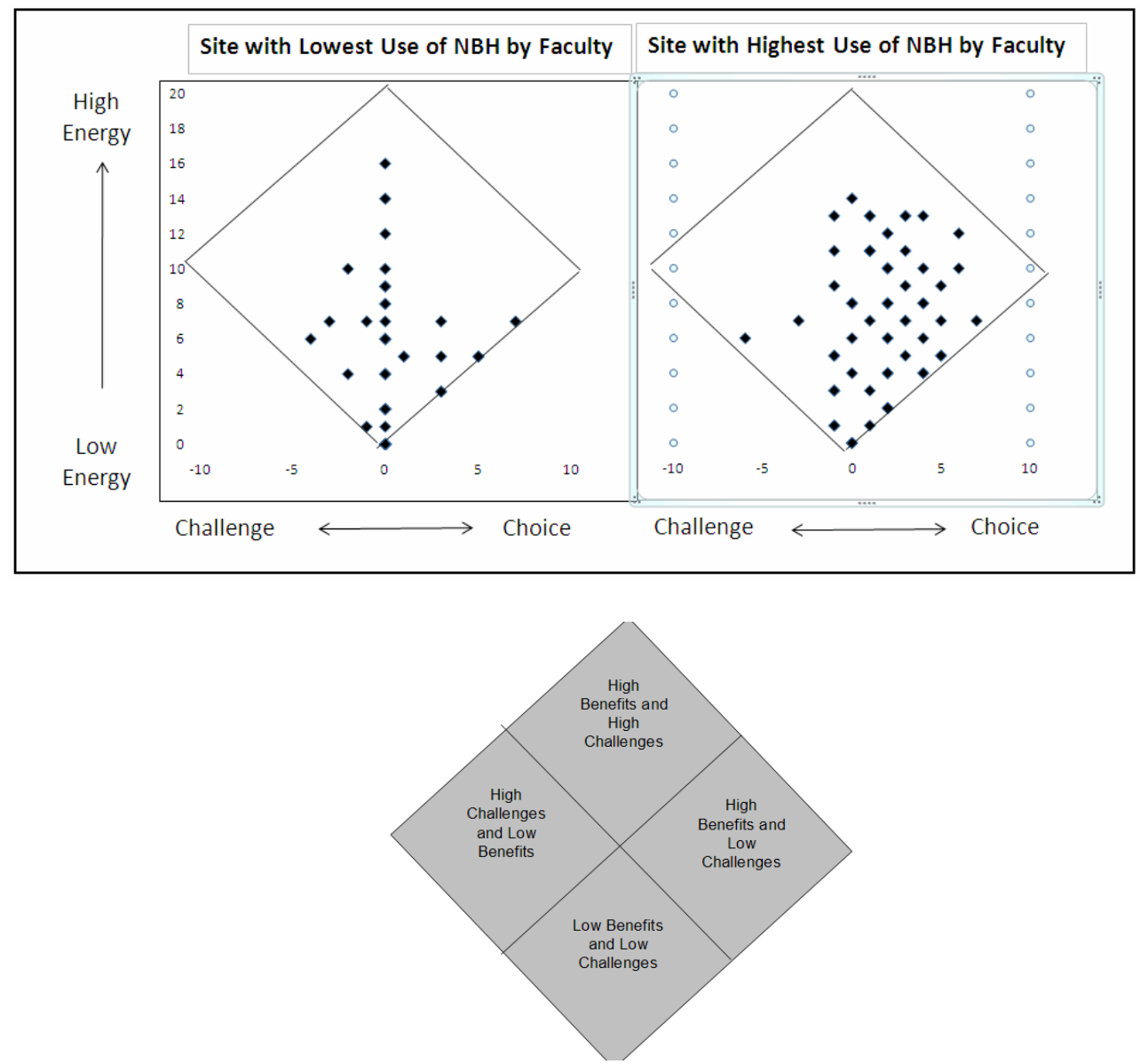

Figure 1. Top: Diamond of opposites analysis comparing the schools with the lowest and highest use. Bottom: Interpretive diagram. NBH indicates The Neighborhood. 
Similarities and differences among participants from the lowest use and highest use schools are noted. Many participants in both groups reported a benefits score that is equal or nearly equal to the challenges score. These values form a vertical line in the middle of each diamond plot from bottom to top, which is seen most prominently in the left plot. This indicates that benefits and challenges grew together. Both schools also had a number of students who reported low benefits and low challenges. The most pronounced difference was that more students from the highest use school (right plot) reported higher net benefits than those from the lowest use school (left plot).

\section{DISCUSSION}

The purpose of this study was to report the benefits, challenges, and relationship between those variables among nursing students using a virtual community. The relationship between use of the intervention and student benefits reported in this study are consistent with findings previously reported by Giddens, Fogg et al. (2010) and Giddens, Shuster et al. (2010), that is, the perceived student benefit is impacted by the frequency of use. Student comments suggest that the intervention brings health-related problems to life through the characters. In bringing those to life, health-related problems are no longer stagnant entities lacking context. The characters' lives provide a framework for students from which they can begin to understand not only health-related issues, but also the multiplicity of factors that may impact the process. As one student said, "It provided a window into real life situations." Comments similar to these were captured in the benefits theme of Enlarged View.

Students asserted that they could relate The Neighborhood characters to real-life situations in their clinical experiences. They also stated that they could relate the stories to what was discussed in class, and they could connect class content and clinical experiences to stories in the virtual community. According to Benner, Sutphen, Leonard, and Day (2010), the integration of clinical and classroom learning provides powerful learning experiences for students. Exposure to patients in a virtual community provides opportunities for integrative learning. Integration was also a predominant theme among another sample of nursing students using the intervention reported by Giddens, Shuster et al. (2010).

This intervention can be compared to providing "a stage," complete with characters, scenery, and action sequences, through which students can learn. Seen from this vantage point, it is not surprising that students repeatedly cite time as one of the challenges of using the virtual community. The amount of time 
required to read stories was also a concern among students reported by Giddens, Shuster et al. (2010). Students must become familiar with the characters before they can make sense of the information found in the story lines. Unlike reading a textbook (a one-dimensional, solitary activity), the virtual community requires higher order thinking. One cannot sit back and "watch the show." Students are required to use critical thinking to interpret, analyze, and synthesize material in the context of the lives of the characters. Thus, learning through a virtual community requires time and energy.

The students who had the highest net benefits were also the most highly challenged; this seemed to be something they valued. These same students also craved even more challenges, additional interactivity with the characters, and the ability to acquire additional information. Students reported net benefits when faculty valued and used the intervention frequently and efficiently. The net student benefits of the intervention increased with faculty use and effectiveness, and increased faculty use was shown to increase student use. One might postulate that The Neighborhood platform is likely to be most effective in engendering an emotional connection with the characters and deep learning when stories are consistently used by the majority of the faculty.

The major limitations of this study were the inability to control the fidelity and use of the intervention across schools and the fact that the level of use was determined only through student report. Another limitation was the organization of the survey. The benefits themes that emerged corresponded to actual survey items that preceded the open-ended comments. Thus, it was possible that the survey items themselves provided prompts for students or for the qualitative coders, who were familiar with the survey items.

\section{IMPLICATIONS FOR NURSING EDUCATION}

It is expected that whenever innovative teaching strategies are introduced, challenges will be encountered not only by students but also by faculty. The analysis of benefits and challenges corroborates the finding that when faculty members do not use the intervention effectively, the benefits barely outweigh the challenges. Thus, one of the most useful findings of this benefits-challenges exploration is the importance of providing initial and ongoing training and support for faculty using virtual communities. It is important that future research focuses on strategies that will increase effective faculty use. Faculty development cannot be expected to occur in a single intervention, but will most likely involve a mentored transformational process over time. Although our initial findings associated with the use of virtual communities in nursing education are 
encouraging, a tremendous amount of work remains. Areas for future research should focus more on actual learning outcomes and actual student performance in clinical areas. The ultimate goal of any educational innovation is to demonstrate improvements in patient care outcomes

\section{REFERENCES}

Benner, P., Sutphen, M., Leonard, V., \& Day, L. (2010). Educating nurses: A call for radical transformation. San Francisco, CA: Jossey-Bass.

Carlson-Sabelli, L., Sabelli, H. C., \& Hale, A. (1994). Sociometry and sociodynamics. In P. Holmes, M. Karp, \& M. Watson (Eds.), Psychodrama since Moreno: Innovations in theory and practice (pp. 145185). London, England: Tavistock/Routledge.

Carlson-Sabelli, L., Sabelli, H. C., Patel, M., \& Holm, K. (1992). The union of opposites in sociometry: An empirical application of process theory. Journal of Group Psychotherapy, Psychodrama and Sociometry, 44(4), $147-171$.

Curran, R., Elfrink, V., \& Mays, B. (2009). Building a virtual community for nursing education: The town of Mirror Lake. Journal of Nursing Education. 48(1), 30-35.

Giddens, J. (2007). The Neighborhood: A web-based platform to support conceptual teaching and learning. Nursing Education Perspectives, 28(5). 251-256.

Giddens, J. (2008). Achieving diversity in nursing through multicontextual learning environments. Nursing Outlook, 56(2), 78-83.

Giddens, J., \& Brady, D. (2007). Rescuing nursing education from content saturation: A case for a concept-based curriculum. Journal of Nursing Education, 46(2), 65-69.

Giddens, J., Fogg, L., \& Carlson-Sabelli, L. (2010). Learning benefits and engagement associated with a virtual community among underrepresented minority students. Nursing Outlook. 58, 261-267.

Giddens, J., Shuster, G., \& Roehrig, N. (2010). Early student outcomes associated with a virtual community for learning. Journal of Nursing Education, 49(6), 355-358. doi: 10.3928/01484834-20100217-03

Hall, E. T. (1984). The dance of life: The other dimension of time. New York, NY: Anchor.

Ibarra, R. (2001). Beyond affirmative action: Reframing the context of higher education. Madison, WI: University of Wisconsin Press. 
National League for Nursing. (2005). Transforming nursing education. Retrieved June 22, 2010, from http://www.nln.org/aboutnln/PositionStatements/ transforming052005.pdf

Sabelli, H. C. (1989) Union of opposites: A comprehensive theory of natural and human processes. Lawrenceville, VA: Brunswick.

Sabelli, H. (2005) Bios. A study of creation with the Bios Data Analyzer. Singapore: World Scientific.

Shuster, G., Giddens, J. \& Roehrig, N. (2011). Emotional connection and integration: Dominant themes among undergraduate nursing students using a virtual community. Journal of Nursing Education. Advance online publication. Retrieved from http://www.journalofnursingeducation. com/advanced.asp.

Stemler, S. (2001). An overview of content analysis. Practical Assessment, Research \& Evaluation, 7(17). Retrieved from http://PAREonline. net/getvn.asp?v=7\&n=17

Walsh, M. (2010). Using a simulated learning environment. Emergency Nurse $18(2), 12-16$.

Young, P., \& Diekelmann, N. (2002). Learning to lecture: Exploring the skills, strategies, and practices of new teachers in nursing education. Journal of Nursing Education, 41, 405-412.

Zull, J. E. (2004). The art of the changing brain. Education Leadership, 62, 68-72. 